\title{
Prospective switch study comparing two irrigation systems for transanal irrigation in children
}

\author{
K. Van Renterghem', M. Sladkov², L. Matthyssens', D. Van De Putte', P. Pattyn', S. Van Biervliet², Saskia Vande Velde \\ (1) Ghent University Hospital, Pediatric Surgery, Ghent, Belgium ; (2) Ghent University Hospital, Pediatric Gastroenterology, Ghent, Belgium.
}

\begin{abstract}
Background and study aims : Transanal irrigation (TAI) is used in children to treat constipation and incontinence. Belgium has 2 systems available: Colotip ${ }^{\circledR}$ (cheaper, however not designed for TAI) or Peristeen ${ }^{\circledR}$.

Patients and methods : This patient-control switch study is the first to compare 2 TAI systems. Children regularly using Colotip ${ }^{\circledR}$ for TAI were asked to participate, after consent, a visual analogue scale (VAS) rating the system and a 2-week diary (fecal continence, self-reliance, time spent on the toilet, pain, Bristol stool scale, irrigation volume and frequency of enema) were completed. Non-parametric statistics were used.

Results : Out of 26 children using Colotip ${ }^{\circledR}, 18$ (69\%) children participated and 5 refused (fear $n=1$, satisfaction Colotip ${ }^{\circledR}$ system $n=7$ ). Of these 18 children (interquartile range: $3-18$ years, median 12.5 years, 9 girls) 5 patients stopped Peristeen ${ }^{\circledR}$ (pain $n=1$, fear $\mathrm{n}=\mathbf{1}$ and balloon loss $\mathrm{n}=3$ ) and 2 were lost from follow up. Dropouts and included patients showed no statistical difference. In the 11 remaining patients, pseudo-continence (p 0.015), independence (p 0.01) and VAS score (p 0.007) were significantly better with Peristeen ${ }^{\circledR}$, no difference was found in time spent on the toilet (p 0.288) and presence of pain ( $p 0.785)$.

Conclusions : In children Peristeen ${ }^{\circledR}$ offered significantly higher pseudo-continence and independency. $30 \%$ refused participation because of satisfaction with the Colotip ${ }^{\circledR}$ and $30 \%$ spina bifida patients reported rectal balloon loss due to sphincter hypotony. To diminish Peristeen ${ }^{\circledR}$ failure, a test-catheter could be of value. Considering Colotip ${ }^{\circledR}$ satisfaction, both systems should be available. Patient selection for Peristeen ${ }^{\circledR}$ needs further research. (Acta gastroenterol. belg., 2021, 84, 295-298).
\end{abstract}

Key words : children, fecal continence, transanal irrigation, colotip, rectal balloon

\section{Introduction}

Transanal irrigation (TAI) is probably used since $1500 \mathrm{BC}$ for different purposes. Currently TAI is used in children for conservative treatment resistant constipation and/ or to achieve fecal pseudo-continence. It is used in both functional and congenital disorders, preferably in a stepwise approach (1).

Two different systems are available to apply TAI: Colotip ${ }^{\circledR}(\mathrm{CT})$ and Peristeen ${ }^{\circledR}(\mathrm{PT})$ (both provided by Coloplast). CT is a re-usable plastic bag with an irrigation cone, originally developed for stoma irrigations. PT is a rectal balloon, first described by Shandling and Gilmour (2), connected to an irrigation bag. The rectal catheter is inserted, and the balloon inflated with air to secure the position of the catheter in the rectum.

In Belgium, the 2 different systems are available, but none is refunded by the health system. CT is a much cheaper system for TAI compared to PT. There is currently no evidence on difference in efficiency or tolerance. This study aims to compare the 2 TAI systems in children with congenital disorders (neurogenic bowel, anorectal malformation and Hirschsprung's disease) in a patient-control switch study.

\section{Method}

In our center, most patients starting TAI use CT because of its lower cost price since there is no reimbursement for TAI. TAI is proposed to children with intractable constipation and/or fecal incontinence due to their underlying disease. TAI will be started depending on patients age and the possibility of stable sitting position on the toilet for the time needed. Parents and patients receive an in-hospital TAI education and demonstration, with the CT using $20 \mathrm{ml} / \mathrm{kg}$ lukewarm tap water. TAI is initially started on daily basis. If successful, in children with a slow transit (confirmed by colon transit time), the frequency can be decreased to every 2 days or 3 times a week.

Children with spina bifida, Hirschsprung's disease and anorectal malformation until the age of 18 years using CT for TAI were included. They were asked to participate, after informed consent, during consultation between November 2016 and 2018. There was no age limitation to start with the study. Before switching to PT, all children were using $\mathrm{CT}$ for at least two months. When switching to PT for TAI, patients and their parents received again an in-hospital education and demonstration of the PT system.

The primary endpoints were fecal pseudo-continence, self-reliance, time spent on the toilet, pain during enema and the visual analog scale (VAS) score of the device used (definitions in Table 1). Other reported parameters were Bristol stool scale (1-7 points), irrigation volume (ml) used and frequency of enema's/ week (daily, every other day, < every 2 days).

Medical information was retrieved from the patients' medical file. Patients completed a two-week diary reporting the various parameters (fecal continence, self-

Correspondence to : Saskia Vande Velde, C. Heymanslaan 10, 9000 Ghent, Belgium. Phone : +3293326468. Fax : +3293322170.

Email : Saskia.vandevelde@uzgent.be

Submission date : 10/09/2020

Acceptance date : 15/09/2020 
Table 1. - Primary endpoints : parameters measured and their definition

\begin{tabular}{|l|l|}
\hline Parameter & Definition \\
\hline Fecal continence & $\begin{array}{l}\text { - Pseudo-continence: no stool loss in the past } 6 \text { months, excluding acute food, viral induced diarrhea } \\
- \text { Social continence: involuntary stool loss }<\text { once monthly } \\
- \text { Fecal incontinence: involuntary stool loss }>\text { once monthly }\end{array}$ \\
\hline Self-reliance & $\begin{array}{l}- \text { Complete self-reliance: no help for the TAI } \\
- \text { Partial self- reliance: limited help from parent/caregiver needed to perform TAI } \\
- \text { Completely dependent: complete TAI process is performed by parent/caregiver }\end{array}$ \\
\hline Time spent on toilet & In minutes \\
\hline Pain & Present or absent \\
\hline VAS score & Visual Analog scale from 1-10 (10 being extremely content with the device used $)$ \\
\hline
\end{tabular}

Table 2. - Results of primary endpoints in total group and differentiated according to underlying etiology

\begin{tabular}{|c|c|c|c|c|c|c|c|c|c|}
\hline & $\begin{array}{c}\text { Total } \\
\text { CT }\end{array}$ & $\begin{array}{c}\text { Total } \\
\text { PT }\end{array}$ & $\begin{array}{l}\text { SB } \\
\text { CT }\end{array}$ & $\begin{array}{l}\text { SB } \\
\text { PT }\end{array}$ & $\begin{array}{l}\mathrm{HD} \\
\mathrm{CT}\end{array}$ & $\begin{array}{l}\text { HD } \\
\text { PT }\end{array}$ & $\begin{array}{c}\text { ARM } \\
\text { CT }\end{array}$ & $\begin{array}{c}\text { ARM } \\
\text { PT }\end{array}$ & $\begin{array}{l}\text { DO } \\
\text { CT }\end{array}$ \\
\hline \multicolumn{10}{|c|}{ Fecal continence } \\
\hline Pseudocontinent & 1 & 8 & 1 & 5 & & 1 & & 2 & 1 \\
\hline Social continent & 7 & 2 & 4 & 2 & 1 & & 2 & & 3 \\
\hline Incontinent & 3 & 1 & 2 & & 1 & 1 & & & 1 \\
\hline \multicolumn{10}{|c|}{ Self-reliance } \\
\hline Complete & 0 & 4 & & 2 & & & & 2 & 2 \\
\hline Partial & 0 & 4 & & 3 & & 1 & & & 1 \\
\hline Dependent & 11 & 3 & 7 & 2 & 2 & 1 & 2 & & 3 \\
\hline \multicolumn{10}{|c|}{ Pain } \\
\hline Absent & $9 / 11$ & $8 / 11$ & $5 / 7$ & $5 / 7$ & $2 / 2$ & $1 / 2$ & $2 / 2$ & $2 / 2$ & $5 / 5$ \\
\hline $\begin{array}{l}\text { VAS score } \\
\text { Median (IQR) }\end{array}$ & $\begin{array}{c}7 \\
(5-8) \\
\end{array}$ & $\begin{array}{c}8 \\
(8-10)\end{array}$ & $\begin{array}{c}8 \\
(5-8) \\
\end{array}$ & $\begin{array}{c}8 \\
(8-10) \\
\end{array}$ & $\begin{array}{c}6 \\
(6) \\
\end{array}$ & $\begin{array}{c}8 \\
(8) \\
\end{array}$ & $\begin{array}{c}7 \\
(6-8) \\
\end{array}$ & $\begin{array}{c}8 \\
(8) \\
\end{array}$ & \\
\hline $\begin{array}{l}\text { Time spent (min) } \\
\text { Median (IQR) }\end{array}$ & $\begin{array}{c}30 \\
(25-90)\end{array}$ & $\begin{array}{c}30 \\
(15-80)\end{array}$ & $\begin{array}{c}40 \\
(25-90)\end{array}$ & $\begin{array}{c}35 \\
(15-80)\end{array}$ & $\begin{array}{c}30 \\
(30)\end{array}$ & $\begin{array}{c}30 \\
(30)\end{array}$ & $\begin{array}{c}25 \\
(20-30)\end{array}$ & $\begin{array}{c}25 \\
(20-30)\end{array}$ & $\begin{array}{c}45 \\
(30-120)\end{array}$ \\
\hline
\end{tabular}

reliance, time spent on the toilet, pain, VAS score, Bristol stool scale, irrigation volume and frequency of enema) while using $\mathrm{CT}$, then changed to the PT system reporting the same parameters in the diary for another two-weeks.

After each study period (CT and PT) a visual analogue scale rating the system was completed independently by the patient and/or parents.

Data were analyzed using IBM SPSS $\AA$, version $25 \AA$ for windows. Results are given as median and interquartile range (IQR). Median differences were compared using non-parametric related samples statistics (Wilcoxon matched-pair signed-rank) to hypothesize a difference in primary endpoints. To compare the proportions on the paired nominal data, the non-parametric Mc Nemar test was used. Significant difference was defined as $\mathrm{p}<0.05$. The study protocol was approved by the ethics committee of the Ghent University Hospital. Informed consent to participate in the study was obtained from patients and/ or parents according to their age. Coloplast provided the Peristeen ${ }^{\circledR}$ system for free.

\section{Results}

The study was proposed to 26 children and adolescents using CT TAI for more than 2 months. Of these, 18 (69\%) patients accepted to participate (IQR: 3-18 years, median 12.5 years, 9 girls). Reasons for refusal were fear for the rectal balloon (1 patient) or satisfaction with the CT system (7 patients). The group refusing PT were spina bifida patients (4/8) and patients with anorectal malformation (4/8), median age was 10 years, IQR: 5-17 years and $5 / 8$ were pseudocontinent.

Of the 18 inclusions, 2 patients were lost from follow up (no information could be gathered) and 5 patients dropped out (DO) after single use. Reasons for single use were balloon loss (3 spina bifida patients), pain (1 Steinert patient) and fear ( 1 spina bifida patient, 7 years old).

Table 2 summarizes the primary endpoints according to the system used and the underlying pathology of the 11 patients $(11 / 26,42 \%)$ as well as the results of the 5 dropouts on CT. No difference was found between the DO group and the group continuing with PT concerning continence, self-reliance, pain and time spent on the toilet.

With CT 8/11 (73\%) were pseudo- or social continent whereas this was the case in 10/11 (90\%) when using PT $(p=0.015)$. No children were self-reliant when using CT. Complete self-reliance was achieved in $4 / 11$ and partial independency was achieved in 4/11 $(\mathrm{p}=0.01), 3 / 11$ were dependent. The VAS score also significantly decreased $(p=0.007)$. Neither the time spent on the toilet $(p=0.288)$ nor the presence of pain $(p=0.785)$ changed. There was no change in secondary outcomes as Bristol stool scale, used volume or TAI frequency.

\section{Discussion}

To our knowledge, this is the first study comparing Colotip ${ }^{\circledR}$ and Peristeen $\AA$ for TAI in children with 
intractable constipation and/or fecal incontinence. Both systems have been reported as being safe instruments for treating constipation and fecal incontinence in children $(3,4)$. No studies have been undertaken to compare treatment results. Choi et al. is the only study reporting outcomes of both systems, however, they proposed CT in children under the age of 6 and PT to children above 6 years of age. They did not compare the treatment results of both systems in the same patient cohort.

Fecal continence and independence of caregivers were important patient driven outcomes reported in studies on quality of life after TAI (4-8). Therefore, this study compared continence and self-reliance as primary outcomes when comparing both irrigation systems. Social and pseudo-continence increased from $73 \%$ with CT to $90 \%$ after two weeks of PT use. The good continence rate was in line with other studies $(3,4,6-10)$, however, longterm results still need to be evaluated.

Going from childhood into adolescence, independency is one of the major aims for the patients. Even in children with chronic treatment aiming towards self-reliance is essential. The CT system was associated with complete dependency whereas $36 \%$ of the patients was able to perform the TAI with PT independently after two weeks use and up to $73 \%$ needed only limited help. There is a possible bias since suggesting independence when using PT could have acted as a motivator of changing habits compared to CT. A randomization for the system from the start of TAI with a longer follow-up could help to unravel this question. Wide et al. could not demonstrate a difference in independency between TAI and antegrade enemas, the latest being considered as a way towards self-reliance (8). Furthermore, upon interrogation many parents felt that their children were unable to obtain independency due to intellectual and/or motor disabilities (11).

The preliminary conclusion of this comparative study was that PT resulted in better continence and selfreliance compared to $\mathrm{CT}$, however there are important considerations to make.

Since a major proportion of patients refused to participate due to satisfaction with CT, there is an important selection bias. In the patient group refusing the study, $1 / 3$ was already continent and partially self-reliant and felt no need to change their TAI system. Again, randomizing for TAI system at the start should be considered.

Furthermore, only 11 patients finished the study. An important drop-out was driven by the impossibility to withhold the balloon in 3 spina bifida patients, fear in 1 (spina bifida, 7 years) and pain (Steinert disease, 13 years) in another patient. Anal sphincter hypotony in spina bifida patients was probably the reason why they could not retain the balloon. King et al reported also important drop out of nearly half of patients (11/20) with PT in a group of spina bifida patients. Reason for drop out: balloon loss in $4 / 20$, too difficult procedure in $4 / 20$ and pain in $3 / 20$ patients (12). Better patient selection (age, underlying disease, personality type, intellectual/ motor disabilities) as well as the use of a try-out catheter could help to select patients able to use PT.

Finally, Choi et al reported the high cost as a reason to stop TAI (5). In Belgium, although available, none of the systems is refundable. Price difference in Belgium is important as CT costs $€ 50,68$ a year while PT in case of daily TAI with a single use rectal catheter costs up to $€ 5.330,64$ a year. This 100 -fold cost increase will put an important strain on patient budget. On the other hand, regarding costs, Emmanuel et al. calculated the cost-savings in a 30 -year-old patient with neurogenic bowel considering increased quality of life, decreased urine tract infections, decreased faecal incontinence episodes and decreased risk for stoma surgery (13). A lifetime cost-saving of $£ 21,768$ ( $€ 25.166,76$ ) per patient was estimated for TAI versus continuing standard bowel care alone. This study demonstrated an increased independence with PT. These are the children when growing up, might be offered an antegrade continence enema as first described by Malone et al, to obtain independence (14). However, surgery comes with a high cost and possible complications. Alenezi et al. offered TAI using PT in a group of 18 children with neuropathic bladder before considering antegrade colon enema. $83 \%$ $(11 / 18)$ became continent and did not need surgery for their bowel problem (15). Governmental discussion should be started to help carry this treatment burden since it is cost saving in the long run in a patient population with already a high health cost.

\section{Conclusion}

Overall, TAI using Peristeen ${ }^{\circledR}$ resulted in a better continence and more independency rate compared to Colotip ${ }^{\circledR}$. Correct patient selection will be important since spina bifida patients are at risk of primary treatment failure due to balloon loss. Even though many patients refused participation due to satisfaction with Colotip ${ }^{\circledR}$, Peristeen ${ }^{\circledR}$ might add additional value for some.

\section{Acknowledgement}

Coloplast for providing 20 peristeen systems and rectal balloon catheters for three months. Authors declare no other conflict of interest.

\section{References}

1. VANDE VELDE S., VAN RENTERGHEM K., VAN WINCKEL M., DE BRUYNE R., VAN BIERVLIET S. Constipation and fecal incontinence in children with cerebral palsy. Overview of literature and flowchart for a stepwise approach. Acta Gastroenterol. Belg., 2018, 81 : 415-418.

2. SHANDLING B., GILMOUR R.F. The enema continence catheter in spina bifida : a successful bowel management. J. Ped. Surg., 1987, 22(3) : 271-273.

3. VANDE VELDE S., VAN BIERVLIET S., VAN LAECKE E., DE BRUYNE R., VERHELST H., HOEBEKE P., et al. Colon enemas for fecal incontinence in patients with spina bifida. J. Urol., 2013, 189 : 300-304.

4. CORBETT P., DENNY A., DICK K., MALONE P.S., GRIFFIN S., STANTON MP. Peristeen integrated transanal irrigation system successfully treats faecal incontinence in children. J. Pediatr. Urol., 2014, 10 : 219-22. 
5. CHOI E.K., SHIN S.H., IM Y.J., KIM M.J., HAN S.W. The effects of transanal irrigation as a stepwise bowel management program on the quality of life of children with spina bifida and their caregivers. Spinal Cord, 2013, 51(5) : 384-388. doi : 10.1038/sc.2013.8. Epub 2013 Feb 26.

6. NG J., FORD K., DALTON S., MC DOWELL S., CHARLESWORTH P., CLEEVE S. Transanal irrigation for intractable faecal incontinence and constipation: outcomes, quality of life and predicting non-adopters. Pediatr. Surg. Int., 2015, 31 : 729-734.

7. MIDRIO P., MOSIEllo G., AUSILI E., GAMBA P., MARTE A., LOMBARDI L., et al. Peristeen transanal irrigation in paediatric patients with anorectal malformations and spinal cord lesions: a multicenter Italian study. Colorectal Dis., 2016, 18(1) : 86-93. doi : 10.1111/codi.13101.

8. WIDE P., MATTSSON G.G., DROTT P., MATTSSON S. Independence does not come with the method-treatment of neurogenic bowel dysfunction in children with myelomeningocele. Acta Paediatr., 2014, 103 : 1159-1164.

9. PACILli M., PALlOT D., ANDREWS A., DOWNER A., DALE L., WILLETTS I. Use of Peristeen transanal colonic irrigation for bowel management in children: a single-center experience. J. Pediatr. Surg., 2014, 49 : $269-72$.
10. MARHUESER S., KARSTEN K., ROTHE K. Improvements in incontinence with self-management in patients with anorectal malformations. Eur. $J$ Pediatr. Surg., 2016, 26 : 186-191.

11. SANDERS C., BRAY L., DRIVER C., HARRIS V. Parents of children with neurogenic bowel dysfunction: their experiences of using transanal irrigation with their child. Child Care Health Dev., 2014, 40(6) : 863-869.

12. KING S.K., STATHOPOULOS L., PINNUNCK L., WELLS J., HUTSON J., HELOURY Y. Retrograde continence enema in children with spina bifida: not effective as first thought. J. Paediatr. Child health, 2017, 53 : 386-390.

13. EMMANUEL A., KUMAR G., CHRISTENSEN P., MEALING $S$., STORLING Z.M., ANDERSON F., et al. Long-term cost-effectiveness of transanal irrigation in patients with neurogenic bowel dysfunction. PLos One, 2016, 11 : e0159394.

14. MALONE P.S., RANSLEY P.G., KIELY E. Preliminary report: the antegrade continence enema. Lancet, 1990, 336 : 1217-1218.

15. ALENEZI H., ALHAZMI H., TRBAY M., KHATTAB A., NEEL K.F. Peristeen anal irrigation as a substitute for the MACE procedure in children who are in need of reconstructive bladder surgery. Can. Urol. Assoc. J., 2014, 8 : E12-15. 